\title{
Food addiction and obesity: do macronutrients matter?
}

\section{Tanya Zilberter* \\ Infotonic Consultancy, Stockholm, Sweden \\ *Correspondence: zilberter@gmail.com}

\section{A commentary on}

Obesity and the brain: how convincing is the addiction model?

by Ziauddeen, H., Farooqi, I. S., and Fletcher, P. C. (2012). Nat. Rev. Neurosci. 13, 279-286.

An article published in April 2012 by the Nature Reviews Neuroscience (Ziauddeen et al., 2012) calls for cautiousness in applying the addiction model to obesity. This scrupulous review described the highly consequential results from B. Hoebel's lab concerning binge-like eating behaviors of rats (Avena et al., 2008, 2009; Bocarsly et al., 2011). Referring to these results, Ziauddeen and colleagues concluded that the binge behaviors relate to the palatability of the foods independently of their macronutrient composition. Earlier, also basing on the works of Hoebel and colleagues, I have been able to draw quite a different conclusion - fat per se, although highly palatable, is not as addictive as carbohydrates and is not obesogenic (Zilberter, 2011). In yet another paper (Peters, 2012), A. Peters interpreted results of Avena et al. (2008) as a proof that "sugar addiction" fails causing obesity. Here, I take a closer look at the Hoebel's model of addiction (Avena et al., 2008, 2009; Berner et al., 2009; Avena, 2010; Avena and Gold, 2011; Bocarsly et al., 2011) while keeping in mind the role of macronutrients.

\section{FOOD ADDICTION}

An opinion exists that rather than an observational link, a causality exists between food addiction and obesity (Gold, 2004; Liu et al., 2006; Corsica and Pelchat, 2010; Johnson and Kenny, 2010). Another opinion is that such a causality does not exist (Peters, 2012) or even that a mere link between them should be considered with caution (Ziauddeen et al., 2012). The caution notwithstanding, it has been shown (and is discussed by Ziauddeen et al., 2012) that drug addiction and food addiction have similar effects, e.g., on the dopaminergic system (Volkow et al., 2008; Gearhardt et al., 2009; Stice and Dagher, 2010) where they "overlap" (Avena et al., 2012). In human subjects, food addiction has been associated with similar patterns of neural activation as substance addiction in anterior cingulated cortex, medial orbitofrontal cortex, and amygdala (Gearhardt et al., 2011b). "Common hedonic mechanisms may therefore underlie obesity and drug addiction," concluded Johnson and Kenny (2010).Addiction liability is being discussed inline with development of obesity pharmacotherapy (Greene et al., 2011).

\section{CARBOHYDRATE ADDICTION}

Carbohydrate (CHO) bias in brain's control of energy homeostasis (Zilberter, 2011) reveals itself in several well known ways including the phenomena termed "positive reward," "hedonism," "wanting," "liking," etc. (Berridge et al., 2010; Gold, 2011). The "sweet-addiction" comparable by magnitude with alcohol addiction (Kampov-Polevoy et al., 2003) and drug addictions (Stoops et al., 2010) is well documented. Gold (2011) argued that deficit in "reward" is coupled with obesity and this coupling is common for sugar, cocaine, and heroin addictions.

Gearhardt et al. (2011b), referring to the aforementioned work of Johnson and Kenny, argued that only "hyper-palatable" foods rich in fat and sugar can cause addiction. Indeed, the combination of fat and sugar resulted in a "reward dysfunction associated with drug addiction and compulsive eating, including continued consumption despite receipt of shocks" (Gearhardt et al., 2011a). A link between food addiction and obesity has also been explicitly postulated (Avena et al., 2009; Corsica and Pelchat, 2010; Gold, 2011).

\section{FAT ADDICTION?}

Studies from B. Hoebel lab suggest that access to $\mathrm{CHO}$ produces different addiction-like behaviors compared with access to fat (Avena and Gold, 2011; Bocarsly et al., 2011; Avena et al., 2012). Nutrient specificity in control of eating behavior was also shown in this lab (Berner et al., 2009). During the "sweet-chow" feeding protocol, rats compensated for the increased sucrose or glucose calories by decreasing chow intake. The authors (Avena et al., 2008) suggested that the increase in sugar intake, while not resulting in obesity, lead to an upregulation of affinity for opioid receptors, which in turn leads to the vicious circle of sugar abuse and might contribute to obesity.

In a later study (Avena et al., 2009), when rats were given intermittent daily access to "sweet-fat" food, they voluntarily restricted their intake of standard chow, similar to what has been reported with "sweet-chow" food (Avena et al., 2008). However, this time rats did become overweight unlike in the "sweetchow" experiment. Authors concluded: "fat may be the macronutrient that results in excess body weight, and sweet taste in the absence of fat may be largely responsible for producing addictive-like behaviors." Yet pure fat, unlike the $\mathrm{CHO}$-fat combination, lacks obesogenity (Dimitriou et al., 2000). Fat combined with limited $\mathrm{CHO}$ content failed to cause overeating and weight gain, while excess $\mathrm{CHO}$ in high-fat diets caused obesity and metabolic impairment (Lomba et al., 2009).

Metabolic studies show that $\mathrm{CHO}$ restriction in high-fat diets exerts neuroprotective effects (Figure 1) via induction of heat-shock proteins (Maalouf et al., 2009), growth factors (Maswood et al., 2004), and mitochondrial uncoupling proteins (Liu et al., 2006). Naturally, CHO excess has neurodeteriorating effects as discussed in Zilberter (2011), Hipkiss (2008), or Manzanero et al. (2011).

\section{CONCLUSION}

Taking into account the well-defined metabolism-related features of a diet can help avoiding ambiguity in definition of diet types and aid in data interpretations. From this standpoint, macronutrients play a crucial role in determining diet's behavioral and metabolic consequences. 


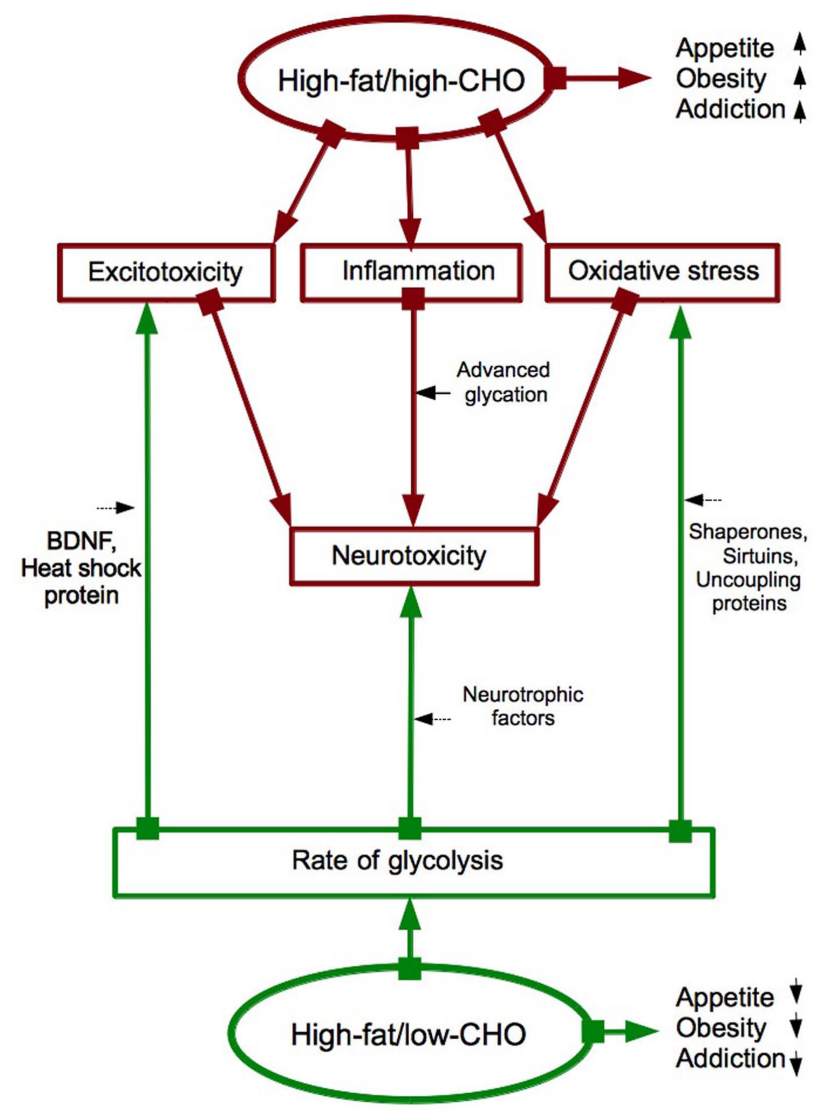

FIGURE 1 | High-fat/high-CHO versus high-fat/low-CHO diets: Addiction, obesity, neurotoxicity and neuroprotection are affected diametrically opposite ways. Summarized from Avena and Gold (2011), Bocarsly et al. (2011), Avena et al. (2012), Berner et al. (2009), Maalouf et al. (2009), Maswood et al. (2004), Liu et al. (2006), Zilberter (2011), Hipkiss (2008), Manzanero et al. (2011). Red arrows: increasing a function or a process. Green arrows: decreasing a function or a process.

\section{REFERENCES}

Avena, N. M. (2010). The study of food addiction using animal models of binge eating. Appetite 55, 734-737.

Avena, N. M., Gold, J. A., Kroll, C., and Gold, M. S. (2012). Further developments in the neurobiology of food and addiction: update on the state of the science. Nutrition 28, 341-343.

Avena, N. M., and Gold, M. S. (2011). Food and addiction - sugars, fats and hedonic overeating. Addiction 106, 1214-1215; discussion 1219-1220.

Avena, N. M., Rada, P., and Hoebel, B. G. (2008). Evidence for sugar addiction: behavioral and neurochemical effects of intermittent, excessive sugar intake. Neurosci. Biobehav. Rev. 32, 20-39.

Avena, N. M., Rada, P., and Hoebel, B. G. (2009). Sugar and fat bingeing have notable differences in addictivelike behavior. J. Nutr. 139, 623-628.

Berner, L. A., Bocarsly, M. E., Hoebel, B. G., and Avena, N. M. (2009). Baclofen suppresses binge eating of pure fat but not a sugar-rich or sweet-fat diet. Behav. Pharmacol. 20, 631-634.

Berridge, K. C., Ho, C. Y., Richard, J. M., and Difeliceantonio, A. G. (2010). The tempted brain eats: pleasure and desire circuits in obesity and eating disorders. Brain Res. 1350, 43-64.
Bocarsly, M. E., Berner, L. A., Hoebel, B. G., and Avena, N.M. (2011). Rats that binge eat fat-rich food do not show somatic signs or anxiety associated with opiatelike withdrawal: implications for nutrient-specific food addiction behaviors. Physiol. Behav. 104, 865-872.

Corsica, J. A., and Pelchat, M. L. (2010). Food addiction: true or false? Curr. Opin. Gastroenterol. 26, 165-169.

Dimitriou, S. G., Rice, H. B., and Corwin, R. L. (2000). Effects of limited access to a fat option on food intake and body composition in female rats. Int. J. Eat. Disord. 28, 436-445.

Gearhardt, A. N., Corbin, W. R., and Brownell, K. D. (2009). Food addiction: an examination of the diagnostic criteria for dependence. J. Addict. Med. 3, 1-7.

Gearhardt, A. N., Grilo, C. M., Dileone, R. J., Brownell, K. D., and Potenza,M.N.(2011a).Can food be addictive? Public health and policyimplications. Addiction 106, 1208-1212.

Gearhardt, A. N., Yokum, S., Orr, P. T., Stice, E., Corbin, W. R., and Brownell, K. D. (2011b). Neural correlates of food addiction. Arch. Gen. Psychiatry 68, 808-816.

Gold, M. S. (2004). Eating disorders, overeating, and pathological attachment to food: independent or addictive disorders? J. Addict. Dis. 23, 1-3.

Gold,M.S. (2011). From bedside to bench and back again: a 30-year saga. Physiol. Behav. 104, 157-161.
Greene, W. M., Sylvester, M., and Abraham, J. (2011). Addiction liability of pharmacotherapeutic interventions in obesity. Curr. Pharm. Des. 17, 1188-1192.

Hipkiss, A. R. (2008). Energy metabolism, altered proteins, sirtuins and ageing: converging mechanisms? Biogerontology 9, 49-55.

Johnson, P.M., and Kenny, P.J. (2010). DopamineD2 receptors in addiction-like reward dysfunction and compulsive eating in obese rats. Nat. Neurosci. 13, 635-641.

Kampov-Polevoy, A. B., Garbutt, J. C., and Khalitov, E. (2003). Family history of alcoholism and response to sweets. Alcohol. Clin. Exp. Res. 27, 1743-1749.

Liu, D., Chan, S. L., De Souza-Pinto, N. C., Slevin, J. R., Wersto, R. P., Zhan, M., Mustafa, K., De Cabo, R., and Mattson, M.P. (2006). Mitochondrial UCP4 mediates an adaptive shift in energy metabolism and increases the resistance of neurons to metabolic and oxidative stress. Neuromolecular Med. 8, 389-414.

Lomba, A., Milagro, F. I., Garcia-Diaz, D. F., Campion, J., Marzo, F., and Martinez, J. A. (2009). A high-sucrose isocaloric pair-fed model induces obesity and impairs NDUFB6 gene function in rat adipose tissue. J. Nutrigenet. Nutrigenomics 2, 267-272.

Maalouf, M., Rho, J. M., and Mattson, M. P. (2009). The neuroprotective properties of calorie restriction, the ketogenic diet, and ketone bodies. Brain Res. Rev. 59, 293-315.

Manzanero, S., Gelderblom, M., Magnus, T., and Arumugam, T. V. (2011). Calorie restriction and stroke. Exp. Transl. Stroke Med. 3, 8.

Maswood, N., Young, J., Tilmont, E., Zhang, Z., Gash, D. M., Gerhardt, G. A., Grondin, R., Roth, G. S., Mattison, J., Lane, M. A., Carson, R. E., Cohen, R. M., Mouton, P. R., Quigley, C., Mattson, M. P., and Ingram, D. K. (2004).Caloric restriction increases neurotrophic factor levels and attenuates neurochemical and behavioral deficits in a primate model of Parkinson's disease. Proc. Natl. Acad. Sci. U.S.A. 101, 18171-18176.

Peters, A. (2012). Does sugar addiction really cause obesity? Front. Neuroenerg. 3:8. doi: 10.3389/fnene.2011.00008

Stice, E., and Dagher, A. (2010). Genetic variation in dopaminergic reward in humans. Forum Nutr. 63, 176-185.

Stoops, W.W., Lile, J.A., and Rush, C. R. (2010). Monetary alternative reinforcers more effectively decrease intranasal cocaine choice than food alternative reinforcers. Pharmacol. Biochem. Behav. 95, 187-191.

Volkow, N. D., Wang, G. J., Telang, F., Fowler, J. S., Thanos, P. K., Logan, J., Alexoff, D., Ding, Y. S., Wong, C., Ma, Y., and Pradhan, K. (2008). Low dopamine striatal D2 receptors are associated with prefrontal metabolism in obese subjects: possible contributing factors. Neuroimage 42, 1537-1543.

Ziauddeen, H., Farooqi, I. S., and Fletcher, P. C. (2012). Obesity and the brain: how convincing is the addiction model? Nat. Rev. Neurosci. 13, 279-286.

Zilberter, T. (2011).Carbohydrate-biased control of energy metabolism: the darker side of the selfish brain. Front. Neuroenergetics 3:8. doi: 10.3389/fnene.2011.00008

Received:18 April 2012; accepted: 02 May 2012; published online: 30 May 2012.

Citation: Zilberter T (2012) Food addiction and obesity: do macronutrients matter? Front. Neuroenerg. 4:7. doi: 10.3389/fnene.2012.00007

Copyright $\odot 2012$ Zilberter. This is an open-access article distributed under the terms of the Creative Commons Attribution Non Commercial License, which permits noncommercial use, distribution, and reproduction in other forums, provided the original authors and source are credited. 